\title{
O acompanhamento de coordenadores pedagógicos por formadores em matemática: uma experiência com tratamento da informação
}

\author{
The accompaniment of the pedagogical coordinators per formers in math: an \\ experience with treatment of the information
}

\author{
Marcela Lopes de Santana \\ ma.santana@yahoo.com.br
}

Daniela Aparecida Baracioli Lemos

dbaracioli@gmail.com

Harryson Junio Lessa Gonçalves

harryson@bio.feis.unesp.br

Inocêncio Fernandes Balieiro Filho

balieiro@mat.feis.unesp.br

\begin{abstract}
Resumo
O presente relato de experiência tem como objetivo contribuir para a reflexão sobre o papel dos Coordenadores Pedagógicos no processo de formação continuada de professores que ensinam Matemática nos anos iniciais do Ensino Fundamental. Pela descrição de encontros de formação com coordenadores, notase como esses profissionais podem fazer uso de estratégias formativas para promover a discussão e ações relativas ao ensino e aprendizagem de Matemática, objeto de conhecimento pouco presente na formação continuada intraescolar, apesar da urgência devido as necessidades dos alunos. Dessa forma, os coordenadores puderam adquirir conhecimentos sobre o seu papel e sobre os conhecimentos matemáticos relativos ao bloco de conteúdo Tratamento da Informação, num processo de colaboração. Concluímos que a figura do Coordenador Pedagógico é essencial para a formação em Educação Matemática dos professores, para que estes aperfeiçoem suas práticas, garantindo a qualidade do processo educativo.
\end{abstract}

Palavras-chave: Coordenador pedagógico; Tratamento da informação; Estatística; Combinatória; Probabilidade.

\begin{abstract}
The present experience's report has as objective to contribute to the reflection about the role of the Pedagogical Coordinators on the formation's process continuous of teachers who teach Math in the initials years of the Elementary School. For the description formation's encounter with coordinators, it is noted how these professionals can make use of formative strategies to promote the discussion and actions related to teaching and learning of Math, object of knowledge absent continuous formation in-school, in spite of urgency due to students' needs. Thus, the coordinators could acquire knowledge about your role and about the mathematicals knowledges related to the content's block Treatment of the Information, in a collaborative process. We conclude that the figure of the Pedagogical Coordinators is essential for the formation in Mathematics Education of the teachers, for them to perfect their practices, ensuring the quality of the educational process.
\end{abstract}

Keywords: Mathematical coordinator; Treatment of the Information; Statistic; Combinatorial; Probability. 


\section{Introdução}

O que faz um Coordenador Pedagógico? Se essa pergunta fosse dirigida a diretores, professores, alunos, pais, funcionários da escola, as respostas seriam muito diversificadas, o que nos leva a duas constatações: o Coordenador Pedagógico é responsável por muitas atividades e poucos sabem, de fato, suas funções e seu papel na escola, até mesmo o próprio profissional. Isso acontece, porque o coordenador costuma ser engolido pela complexidade da rotina escolar e, dia após dia, segue "apagando os incêndios" com os quais se depara. Telefonemas, burocracia, organização de espaços, reuniões, atendimento a pais, alunos, professores, auxílio ao diretor. No entanto, o seu papel principal consiste em propiciar a formação de professores e se (co)responsabilizar pelo processo ensinoaprendizagem. Conquistar parceria com os professores para acompanhar a prática pedagógica também não é tarefa fácil e esse aspecto colabora para que o coordenador se sinta perdido em suas funções.

Assim, o presente artigo tem como objetivo promover a reflexão sobre o papel do coordenador pedagógico no processo de formação continuada de professores que ensinam Matemática nos anos iniciais do Ensino Fundamental a partir de uma experiência de formação realizada no município de São José do Rio Preto (SP), com 39 Coordenadores Pedagógicos (responsáveis pelas 39 escolas de Ensino Fundamental do Município) agrupados em cinco polos, compostos de sete ou oito coordenadores, muitas vezes acompanhados pelos Supervisores de Ensino de suas escolas que participaram como ouvintes. Os encontros denominados Reuniões de Acompanhamento por Agrupamentos de Coordenadores Pedagógicos aconteceram na Secretaria Municipal de Educação de São José do Rio Preto uma vez por mês, de fevereiro a novembro de 2016, em um total de nove encontros de três horas cada, com exceção de agosto, mês em que aconteceu o Seminário de Boas Práticas. Cada polo contou com duas formadoras, uma para Língua Portuguesa e uma para Matemática e aqui nos concentramos apenas nos conteúdos de Matemática. A equipe de Matemática, composta de cinco formadores, incluindo as duas primeiras autoras do presente artigo, elabora as pautas das reuniões.

\section{O Papel do Coordenador Pedagógico na Formação de Professores}

A figura do coordenador, de acordo com Zen (2012), inicialmente era de inspetor escolar, com função de controle sobre a prática pedagógica. Na década de 1980, com a discussão sobre democratização do ensino, a formação de professores se torna meio de garantia para elevação da qualidade do ensino. Os estudos indicavam a reflexão, análise e 
problematização da prática como ferramenta de formação. O Coordenador Pedagógico passa a ser, então, um articulador na comunidade escolar e principal responsável pela formação de professores em um processo de construção coletiva. E precisa se valer de estratégias formativas, em diferentes espaços formativos, para ajudar o professor a qualificar o seu trabalho.

Entretanto,

Não é de qualquer jeito que se faz formação de professores. Para realizar um trabalho de qualidade, é preciso conhecer a discussão sobre o objeto de conhecimento e sobre os processos de aprendizagem, tanto dos alunos como dos professores. (ZEN, 2012, p. 10)

Conhecer o objeto de conhecimento de alunos e professores requer estudo, o que nem sempre é observável no cotidiano do coordenador. O planejamento de sua rotina precisa estar em dia para que este se organize na realização de suas atividades. $O$ Coordenador Pedagógico também precisa estar em constante formação e autoformação e, portanto, é um profissional que se forma enquanto forma.

No que se refere à Matemática como objeto de conhecimento, percebe-se que, apesar da urgência de discussão em torno desse componente curricular em razão das necessidades de aprendizagem dos alunos, esta se faz pouco presente nos processos formativos intraescolares. Andrade, Barbosa e Martins (2015), em uma pesquisa realizada em 25 escolas de um município do Estado de São Paulo, que tem o Ler e Escrever como política pública instalada, avaliam o lugar da Matemática nas reuniões pedagógicas das escolas e percebem uma centralidade dos assuntos de Língua Portuguesa nas reuniões de professores, devido à alfabetização. Enquanto isso, a Matemática ocupa poucos espaços de discussão e há poucas evidências de um trabalho programado pelo Coordenador Pedagógico nas reuniões.

De acordo com Ponte (2005), a Educação Matemática traz contributos importantes para compreender o conteúdo e os processos formativos relativos ao professor de Matemática. Pires (2012) acrescenta que tal área é uma área do conhecimento interdisciplinar "que incorpora dimensões filosóficas, históricas, psicológicas, políticas, metodológicas e culturais na busca por melhor entendimento sobre os processos de ensino e aprendizagem da Matemática, bem como o papel social e político" (p. 14).

A formação continuada, assim como a inicial, ao longo de muitos anos permaneceu apoiada na lógica de refletir sobre aspectos políticos e pedagógicos ou oferecer estratégias didáticas para melhoria das práticas. 


\begin{abstract}
A suposição de que os professores conhecem os conteúdos que precisam ensinar sempre esteve presente. Desta forma, bastaria discutir estratégias de ensino ou questões relativas a concepções filosóficas, sociológicas e políticas da Educação que, sem dúvida, permeiam as justas exigências da universalização da educação. No entanto, nos últimos anos, a meta da universalização foi atingida sem que a necessária meta da qualidade da educação oferecida às nossas crianças acompanhasse esse processo. (MANDARINO, 2008, p.2)
\end{abstract}

Considerando que é sempre possível discutir sobre os conteúdos a serem ensinados e as formas de fazê-lo para apoiar o aprimoramento da qualidade da educação, o Município de São José do Rio Preto - SP realiza reuniões de acompanhamento por agrupamentos de Coordenadores Pedagógicos, espaço para esses profissionais discutirem em grupos pequenos, reunidos considerando algumas semelhanças entre as escolas, a formação de seus professores em Matemática (e Língua Portuguesa), seja ela externa ou interna à escola, bem como as demandas de sua realidade. Tem por objetivo subsidiar o Coordenador Pedagógico para o acompanhamento do trabalho dos professores, aliando as duas instâncias de formação (de professores e de coordenadores) e aperfeiçoando a formação oferecida nas escolas, nos espaços coletivos.

Paralelamente ao acompanhamento de coordenadores, há a formação de professores que ao longo dos últimos seis anos vem aprofundando o conhecimento dos professores em relação aos diferentes blocos de conteúdo dos PCN, Números e Operações, Espaço e Forma, Grandezas e Medidas e Tratamento da Informação. No ano de 2016, buscou-se ampliar a visão sobre os conteúdos do bloco Tratamento da Informação, portanto, a formação de coordenadores colocou esse profissional a par da discussão realizada com os professores para que pudesse acompanhá-los no planejamento das aulas, execução e avaliação dos avanços os alunos no decorrer do processo. Ao mesmo tempo, esse conteúdo foi um viés para tratar de procedimentos inerentes a função do Coordenador Pedagógico, como o acompanhamento do planejamento das aulas; a observação de sala pautada na organização do espaço e do tempo, na qualidade das interações e intervenções, no reconhecimento dos saberes dos alunos, no avanço quanto as suas aprendizagens e na sistematização dos conhecimentos historicamente acumulados; ainda, nas devolutivas ao professor, no estímulo a reflexão sobre o seu fazer pedagógico, nas práticas colaborativas; nas tematizações da prática, dentre outras estratégias formativas.

Os encontros consideram a homologia de processos que "tem como fundamento a adoção de semelhança na estrutura e nas etapas que compõem o processo formativo dos 
educadores e a práxis pedagógica que desenvolve junto aos alunos" (SALVADOR, 2012, p. 47). Assim, quando se deseja uma prática reflexiva e problematizadora na escola, a metodologia utilizada na formação também deve considerar tais aspectos. Ao se almejar um trabalho colaborativo, o uso de situações em grupos, as socializações de raciocínios, é preciso estimular isso nos processos formativos.

\section{O Coordenador Pedagógico, a Observação de Sala e os Registros Reflexivos em Tratamento da Informação}

Nas primeiras reuniões com Coordenadores Pedagógicos, após a contextualização do que fora trabalhado na formação de professores de todos os anos, de primeiro ao quinto, propôs-se que os coordenadores acompanhassem os professores nas adaptações necessárias do planejamento elaborado em grupos na formação de professores, de maneira que esse estivesse de acordo com as diferentes realidades e necessidades dos alunos de cada escola. Pautando-se no Instrumento de Apoio, adaptado de Reis (2011), o coordenador deveria além de acompanhar esse planejamento, observar a aula de um professor que se mostrasse aberto para isso e enviar aos formadores um registro reflexivo desse processo.

Na publicação Coordenador Pedagógico: caminhos, desafios e aprendizagens para a prática educativa, da Secretaria Municipal de Educação de Salvador (SALVADOR, 2012), a observação de sala é apontada como uma oportunidade de compreensão de toda complexidade do ato educativo, uma possibilidade do Coordenador Pedagógico refletir in situ sobre este, não se baseando apenas no relato de outros. Constitui-se ferramenta de formação, a medida que o Coordenador oferece ao professor um outro olhar para refletir sobre o que sozinho não é possível visualizar em relação a sua própria prática. Esse objeto de trabalho do coordenador precisa romper com a tradição de fiscalização e promover relações de confiança e parceria, o que requer alguns cuidados como o estabelecimento um foco de observação de acordo com o plano de formação do Coordenador e o planejamento conjunto com o professor para o registro da situação observada. Convidar o professor para refletir e se manifestar sobre a sua própria prática, construindo junto a devolutiva da qual necessita, por meio de problematizações, buscando sempre elementos positivos que validem a prática docente a fim de fortalecê-la para encaminhamentos futuros também são cuidados essenciais para que esse recurso seja, de fato, formativo.

$\mathrm{Na}$ sequência de encontros com Coordenadores Pedagógicos, novamente contextualizou-se os conteúdos trabalhados na formação de professores, para que os coordenadores continuassem acompanhando o trabalho com Tratamento da Informação 
desenvolvido em suas unidades escolares. Os coordenadores relataram como foi a observação da aula em sua escola sobre Tratamento da Informação e receberam o feedback da Formação sobre seus registros reflexivos, onde identificou-se a presença de práticas colaborativas entre os professores, acompanhamento do planejamento pelos coordenadores, presença do conteúdo na rotina semanal docente e iniciativas criativas de articulação com outros blocos de conteúdos, principalmente, Grandezas e Medidas e, até mesmo, o uso da História da Matemática. Foram compartilhadas com os coordenadores as fotos de boas práticas: gráficos montados a partir do próprio corpo em vários espaços da escola: gráficos coletivos, na lousa digital, no laboratório de informática, traçado livre, produção de textos a partir de gráficos e tabelas, gráficos a partir de obras de arte e o trabalho de Combinatória de apenas uma escola - vide exemplos nas figuras 1 e 2 .

Figura 1: Fotografias dos coordenadores da rede municipal (gráficos)

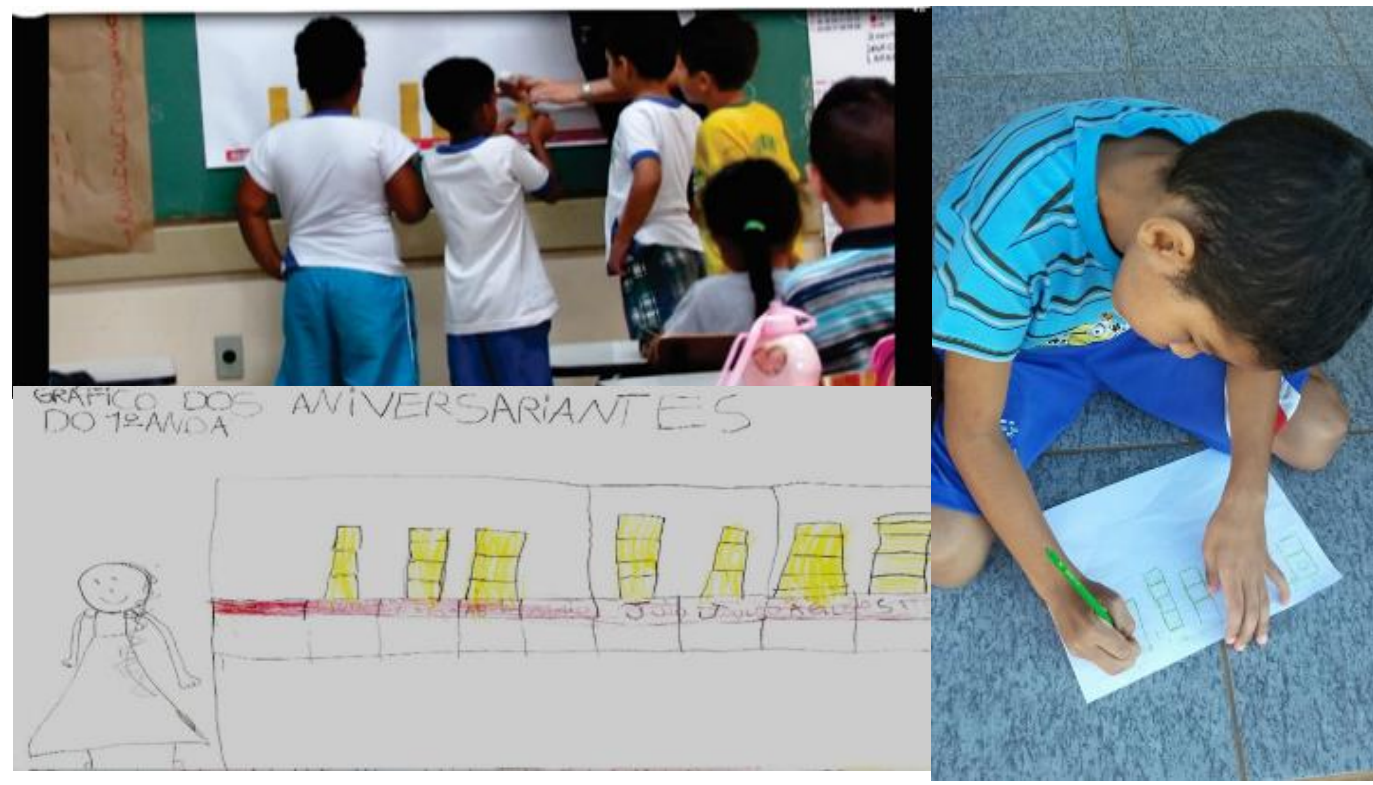

Legenda: gráfico coletivo de aniversariantes (fotografia da esquerda, superior); traçado livre (fotografia da direita); protocolo de aluno (fotografia da esquerda, inferior)

Fonte: Coordenadores da rede municipal.

Apesar das situações didáticas apresentadas partirem da realidade dos alunos, poucas estavam ligadas a problemas da esfera social, ficando contextualizadas em uma realidade muito próxima, quase restrita à sala de aula. Exploravam uma significativa variedade de recursos didáticos, contudo ficavam mais no âmbito da Estatística, não contemplando propostas de Combinatória e Probabilidade. Havia uma lacuna também em Estatística, já que não se observava o trabalho com a pesquisa e o estímulo ao pensamento 
autônomo para elaboração mental dessa organização dos dados em gráficos e tabelas, sendo que são induzidos antes mesmo dos alunos experimentarem organizar os dados fora deles. Pelos registros concluímos que a pesquisa, a coleta e organização autônoma dos dado por parte dos alunos, além do trabalho com Combinatória e Probabilidade constituiam necessidades formativas para o ano de 2016.

Figura 2: Fotografias dos coordenadoes da rede municipal

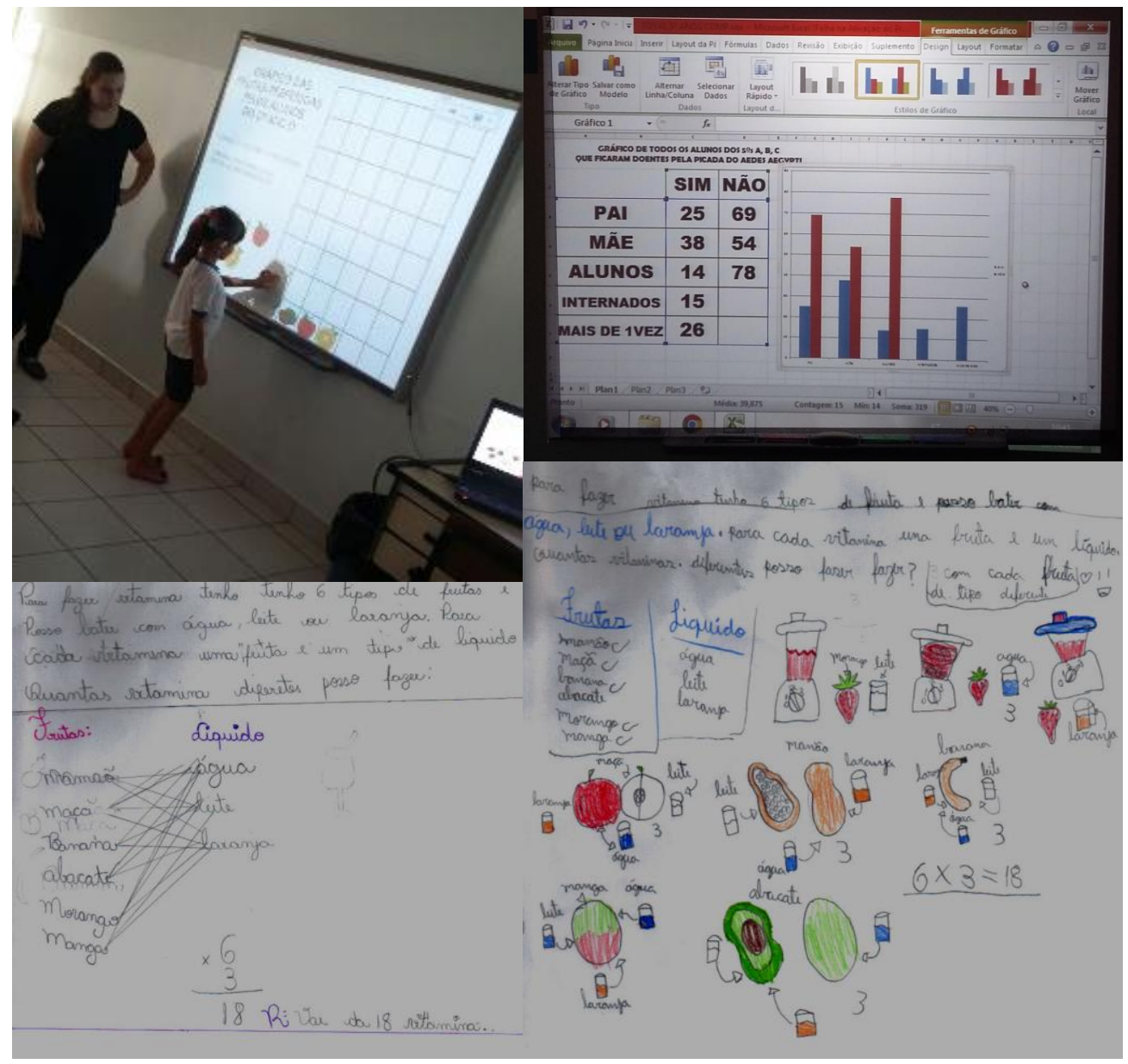

Legenda: gráfico de frutas preferida na lousa digital (fotografia da esquerda, superior); tabela e gráfico construídos pelos alunos no Laboratório de Informática (fotografia da direita, superior); protocolo de alunos: resolução de problema combinatório por diferentes procedimentos (fotografias da esquerda e direita, inferior)

Fonte: Coordenadores da rede municipal.

Sobre o trabalho com Estatística, Guimarães (2014), afirma que:

Não precisamos apenas tratar os dados, precisamos muito mais do que isso, precisamos ensinar nossos alunos a PESQUISAR. Tratar os dados é apenas uma das fases da pesquisa. [...] É preciso pensar o ensino numa perspectiva de envolver os alunos ativamente no planejamento da pesquisa e na busca de dados reais para responder questões práticas do cotidiano. (GUIMARÃES, 2014, p. 1819) 
Dessa forma, buscamos nos passos seguintes, por meio da literatura referente à Tratamento da Informação e por estratégias formativas que serão descritas a seguir, levar o coordenador a compreender a importância da observação de sala referente à Estatística considerando Quem planejou a pesquisa (aluno ou professor)? Qual a ligação desta a uma necessidade real do contexto? Qual o grau de autonomia do aluno na experimentação da organização dos dados por procedimentos próprios ainda que não convencionais? Se há socialização das formas de registros? Se a organização de dados que se faz presente nas diferentes esferas de comunicação é considerada como fonte de consulta para evolução dos registros posteriores? E se chega-se a uma conclusão crítica do que está categorizado?

\title{
4. Tematizando a prática com Coordenadores Pedagógicos: a Estatística em vídeo
}

De acordo com Guimarães (2014), ser letrado estatisticamente significa saber se posicionar diante de uma informação de modo crítico, entender dados, comunicá-los e tomar decisões a partir deles. O pensamento estatístico envolve o mundo das incertezas e é fundamental para os alunos

\begin{abstract}
A vivência de situações nas quais o indivíduo possa pensar problemas, elaborar questões, levantar hipóteses, definir amostras, escolher os instrumentos e a forma de coletar os dados, classificá-los, registrar informações, interpretá-las e chegar às conclusões possíveis diante do que foi realizado, sempre avaliando cada fase e a relação da mesma com o todo. Enfim, desenvolver o espírito investigativo natural do ser humano. (GUIMARÃES, 2014, p. 19)
\end{abstract}

Das boas práticas enviadas pelos Coordenadores Pedagógicos, tematizamos um vídeo em que a professora propõe a elaboração de um texto coletivo a partir dos dados de um gráfico.

Lerner, Torres e Cuter (2007), abordam a análise de situações de sala de aula como a estratégia formativa que mais fornece dados para a reflexão. A tematização da prática cria questões que dão sentido ao estudo de bibliografia, faz com que o professor veja a situação sobre outras perspectivas, elabore propostas de intervenção didática. A análise de registros de vídeo ou por escrito, fornece uma amostra da prática real e torna possível abordar a complexidade do objeto que se deseja estudar, permitindo propor problemas sobre as hipóteses das crianças, as interações, a concepção de ensino e aprendizagem por trás de cada proposta. $\mathrm{O}$ trabalho consiste em identificar os aspectos relevantes, isolar conhecimentos didáticos possíveis de generalização, potencializando conhecimentos que poderão ser utilizados em outras situações. É preciso pensar em questões que permitam 
descontextualizar o que está contextualizado, saber onde colocar o olhar, tornando os conteúdos observáveis para o professor. A reflexão realizada em pequenos grupos é compartilhada com os outros professores e com as intervenções do formador favorece a análise gradualmente descontextualizada e recontextualizada no momento do planejamento. A análise de aulas realizadas em outros contextos favorece a problematização e a reformulação de antigas práticas, faz com que os professores avancem na contextualização de condições e intervenções didáticas. A reflexão sobre práticas próprias propicia uma melhor compreensão das complexas relações de ensino e aprendizagem e fundamenta ações futuras.

Produzir textos a partir de tabelas e gráficos pode ser um excelente recurso para promover a leitura dos dados e análise e interpretação efetiva, desenvolvendo com os alunos o senso crítico a respeito das informações que eles veiculam.

Smole e Diniz (2001), dizem, a respeito da produção de textos em Matemática:

Pensamos ser necessário falar sobre as intervenções que o professor pode fazer nos textos de seus alunos também no que diz respeito às informações matemáticas, para que estes se apropriem do vocabulário específico, utilizem-no, evoluam na compreensão dos significados das noções e dos conceitos matemáticos e possam perceber a importância de expressá-los com precisão. (SMOLE \& DINIZ, 2001, p. 47)

Pires (2012), afirma que produzir textos escritos pela interpretação de gráficos e tabelas e, construir gráficos e tabelas com base em informações de textos jornalísticos e científicos, são propostas que merecem a atenção do professor.

Os coordenadores concluíram que os vídeos são excelentes situações para refletir sobre a prática; que a situação filmada era uma ótima situação de aprendizagem para as crianças que já sabiam ler gráficos e tinham destreza para ditar o texto à professora, demonstrando o hábito de realização desse tipo de atividade. Entretanto concluíram que o trabalho ainda precisava de maiores investimentos na análise dos dados de modo que as crianças não só os relatassem, mas que refletissem, inferissem, opinassem sobre eles.

A sistematização foi feita com um vídeo do Salto para o Futuro $^{1}$ que citava as etapas da pesquisa e complementado pelo texto Estatística nos anos iniciais, de Gilda Guimarães (2014).

Como já havíamos abordado observação de sala, os próximos encaminhamentos seriam no sentido de dar uma devolutiva ao professor, entendendo devolutiva como um

${ }^{1}$ Disponível em: <http://tvescola.mec.gov.br/tve/video?idItem=7102> Acesso em: 29 dez.2016. 
retorno após uma observação de sala, momento de parceria entre coordenador pedagógico e professor. Para discutir o assunto, propusemos a elaboração de uma devolutiva sobre uma situação fictícia supostamente observada e registrada, em Tratamento da Informação. Os coordenadores deveriam dar sugestões para o enriquecimento da proposta, levando o professor a refletir sobre a autonomia e protagonismo das crianças no processo de pesquisa, coleta e organização dos dados. A situação criada representava o observado pelos formadores em Matemática em várias práticas enviadas, ou seja, a construção de gráficos e tabelas sempre no coletivo, ou o trabalho com malha quadriculada totalmente direcionado para a construção de gráficos e tabelas padronizadas, sem que a criança refletisse sobre como organizar os dados e registrá-los, livremente, observando os procedimentos dos outros alunos para irem se aproximando das formas de registros convencionais sem imposições).

Tal devolutiva se caracteriza como o momento em que coordenador e professor refletem juntos sobre a experiência e planejar encaminhamentos para uma atuação mais fortalecida: o coordenador não deve fazer a reflexão pelo professor. O professor precisa ser convidado a falar, sentindo-se seguro e respeitado. O coordenador é um problematizador que vai oferecendo elementos para reflexão, buscando elementos positivos na prática do professor e orientando pontos não abordados (SALVADOR, 2012).

\section{Combinatória e Tematização da Prática}

O objetivo do ensino de Combinatória nos anos iniciais do Ensino Fundamental é possibilitar aos alunos lidarem com situações-problema que envolvam tipos de agrupamentos diferentes, aproximando-os do princípio multiplicativo da contagem (PIRES, 2012). E ainda, o trabalho com os diferentes tipos de problemas combinatórios possibilita um amplo desenvolvimento do raciocínio combinatório (PESSOA; BORBA, 2009a).

Podemos definir - a partir de Borba, Batista e Azevedo (2015) -quatro tipos diferentes de problemas combinatórios: produto cartesiano, combinação, arranjo, permutação.

Os produtos cartesianos são os problemas nos quais se combinam elementos de um conjunto com elementos de outro(s) conjunto(s). [...]

Nas combinações, elementos de um conjunto único são combinados e nos quais a ordem dos elementos não indica possibilidades distintas. [...]

Nos arranjos, ao contrário das combinações, a ordenação dos elementos indica possibilidades distintas. [...]

Um quarto tipo de situação combinatória são as permutações, nas quais todos os elementos aparecem em todas as possibilidades, variando apenas a ordem deles. (BORBA, BATISTA E AZEVEDO, 2015, p. 26-27) 
Prosseguindo o trabalho em Tratamento da Informação realizamos filmagens em três salas de aula da rede. Escolhemos um segundo ano, um terceiro e um quarto, ou seja, uma sala de Ciclo I, uma de Ciclo II e uma que fica na transição entre os dois ciclos ${ }^{2}$ dos anos iniciais para filmagem. Pretendíamos mostrar aos coordenadores como crianças dos anos iniciais podem resolver problemas de Combinatória. Além disso, também almejávamos colocar em evidência a Tematização da Prática, estratégia formativa que pode ser desenvolvida dentro da escola para aprimorar o trabalho dos professores.

Como para cada sala propusemos a resolução de um problema com uma ideia diferente de Combinatória, no primeiro momento desse encontro de Coordenadores pedimos para que eles experimentassem resolver os problemas da filmagem sem utilizar fórmulas (vide figura 3).

Figura 3: Protocolos de resolução de problemas

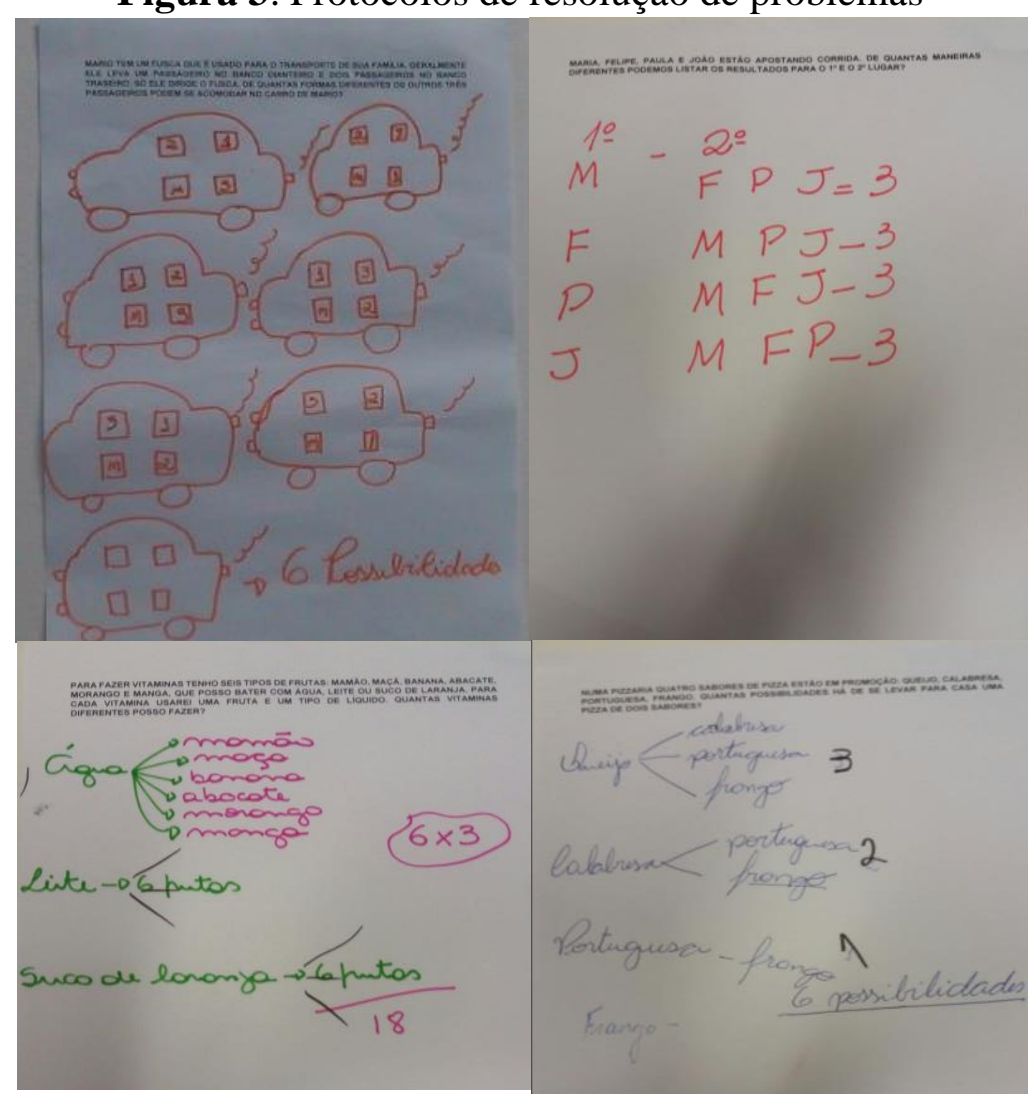

Legenda: problema de permutação (fotografia da esquerda, superior); problema de arranjo (fotografia da direita, superior); problema de produto cartesiano (fotografias da esquerda, inferior); problema de combinação (fotografias da direita, inferior)

Fonte: acervo de uma das formadoras.

\footnotetext{
${ }^{2}$ Os anos iniciais do Ensino Fundamental de Nove Anos, nas escolas municipais de São José do Rio Preto estão divididos em dois ciclos, Ciclo $\mathrm{I}-1^{\circ}$ ao $3^{\circ}$ ano, Ciclo II $-4^{\circ}$ e $5^{\circ}$ ano.
} 
Foto 4: Socialização dos protocolos de resolução de problemas combinatórios pelos Coordenadores Pedagógicos

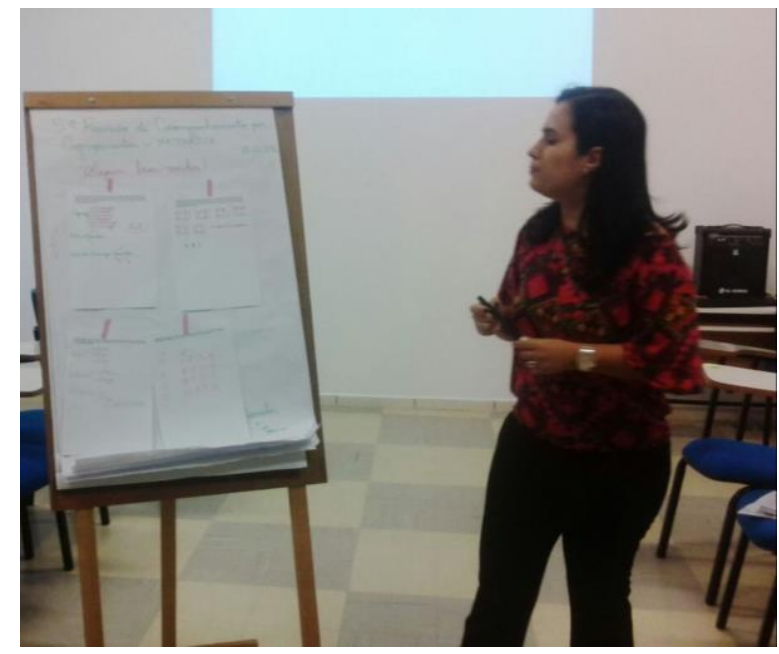

Fonte: Acervo das formadoras

Dando continuação ao encontro, foi contextualizada a situação de filmagem, explicitando que houve o planejamento com coordenadores e professores das escolas envolvidas, assegurando os seguintes aspectos: um problema para levantamento das ideias iniciais dos alunos sobre Combinatória e um quadro organizador dos saberes dos alunos, que serviu de norte para organização das duplas produtivas e a situação-problema filmada.

O primeiro trecho de vídeo teve o intuito de dar luz às intervenções da professora, $o$ segundo, às estratégias dos alunos e o terceiro, à socialização de diferentes estratégias de resolução pelos alunos e à sistematização realizada pela professora.

Os vídeos foram editados, sendo exibidos recortes de 5 a 10 minutos. No primeiro trecho de vídeo exibido, o de arranjo, para que o grupo de coordenadores refletisse sobre as intervenções da professora propusemos a seguinte pergunta norteadora: "Como a professora interviu para que cada dupla compreendesse o problema?”.

$\mathrm{O}$ vídeo exibiu os procedimentos da professora com três duplas. Na primeira, os alunos conseguiram fixar um elemento, esgotar as possibilidades fazendo as trocas, porém, não conseguiram contar as possibilidades. A professora realizou várias problematizações e aproveitou o raciocínio de um aluno da dupla para levar o outro a compreender. $\mathrm{Na}$ segunda, a professora não conseguiu fazer a aluna esgotar as possibilidades no momento da resolução. Na socialização das diferentes estratégias de resolução pelos alunos na lousa, a professora utilizou-se da comparação de estratégia de resolução semelhante a da aluna para que ela compreendesse que havia mais possibilidades do que imaginava - por meio de problematizações e pelo diálogo com o outro aluno, levou-a a entender o raciocínio 
combinatório envolvido na resolução do problema. Na terceira dupla, a professora entregou o material manipulativo e acompanhou a sua utilização problematizando a situação a fim de que a dupla esgotasse todas as possibilidades.

Como intervenções os coordenadores citaram a formação das duplas produtivas pela resolução individual de um problema combinatório, o uso de folha única para viabilizar o trabalho em dupla, a circulação da professora pela sala solicitando explicações das crianças sobre o raciocínio empregado para resolver a situação problema, a contagem das possibilidades, as boas perguntas que desestabilizassem, provocando conflitos e o aproveitamento dos saberes de um aluno para o questionamento de outro. Tais intervenções foram elencadas rapidamente no flip chart no momento da socialiazação, conforme figura 5.

Foto 5: Registro das respostas dos Coordenadores Pedagógicos no Porta Texto

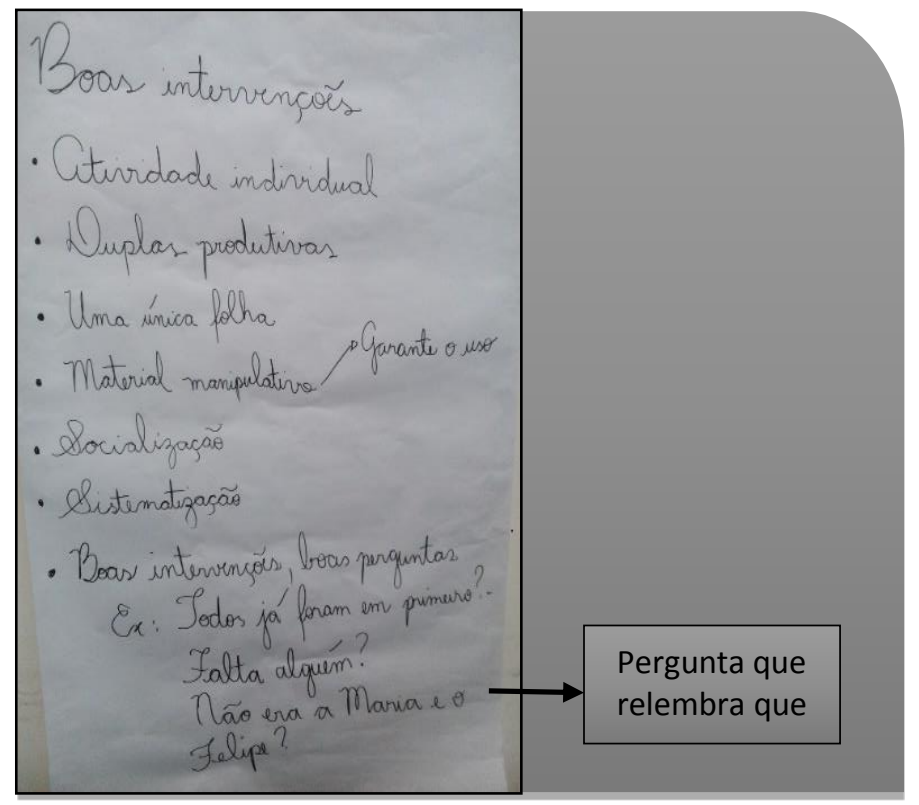

Fonte: Acervo das formadoras

Os trechos do vídeo que mostravam intervenções da professora foram voltados para identificar na problematização as perguntas que mais promoveram a reflexão das crianças, por exemplo: "Com quem Maria não foi ainda?" (auxílio para encontrar mais possibilidades); “Quem está em primeiro na dupla?”; “Quem mais pode ir em segundo com João?”; “A gente não tem que contar as duplas de $1^{\circ}$ e $2^{\circ}$ lugar?"(auxílio para contagem das possibilidades); “A Maria foi em primeiro? O João também? O Felipe também? Falta ir alguém?”; “Quantas possibilidades são?”. 
O segundo trecho do vídeo de aula foi exibido após a análise de protocolos de resolução dos alunos fotocopiados para esse fim. Os Coordenadores Pedagógicos deveriam observar como os alunos demonstravam compreender as relações combinatórias. $\mathrm{O}$ levantamento de hipóteses sobre o raciocínio empregado pelos alunos e a comparação posterior com o vídeo causaram grande surpresa sobre como as crianças são capazes de construir o pensamento combinatório.

O terceiro vídeo exibido, do $4^{\circ}$ ano, teve como foco de observação a socialização e sistematização realizada pela professora com as crianças que resolveram de diferentes formas uma situação problema de permutação. A professora garantiu durante a socialização a fixação de elementos, a contagem das possibilidades, a observação do número de vezes que cada passageiro sentou em cada lugar e a estratégia melhor para visualização.

Após esses estudos foi proposto que os coordenadores fizessem o planejamento com um professor de sua escola sobre uma situação problema a ser aplicada em sala de aula, a filmagem, a devolutiva e, posteriormente, a Tematização da Prática com os professores de mesmo ano/ciclo.

No encontro seguinte, refletimos juntos se a Tematização da Prática é um bom recurso para problematizar e reformular antigas práticas e promover avanços nas condições e intervenções didáticas oferecidas e melhorias nas relações ensino $e$ aprendizagem?.

Os coordenadores citaram os impactos positivos dessa estratégia formativa; conversamos sobre como olhar para os registros para eleger um foco de análise e sobre a questão que direciona o olhar do professor na mesma direção, bem como os fundamentos teóricos que subsidiam a análise da prática observada.

\section{Experimentação e reflexão em colaboração com Coordenadores Pedagógicos: Uma situação de Probabilidade}

Santana e Borba (2016), afirmam que a escola atual deve estimular a formação de conceitos de natureza probabilística desde o ensino fundamental. Remetem-se aos Parâmetros Curriculares Nacionais (PCN) para dizer que grande parte dos acontecimentos do cotidiano são de natureza aleatória e que as ideias de acaso e incerteza se manifestam intuitivamente nos indivíduos, sendo a escola a responsável por propiciar aos alunos 
situações onde possam realizar experimentos, observar eventos construindo o raciocínio probabilístico.

Formulamos a pauta desse encontro com base na leitura de artigos, análise de situações de livros didáticos e no jogo Sete Cobras (figura 6), presente no Caderno de Formação de Professores ${ }^{3}$ da Universidade Estadual Paulista "Júlio de Mesquita Filho (UNESP) e Universidade Virtual do Estado de São Paulo (UNIVESP). O jogo consiste em lançar dois dados e somar as quantidades obtidas marcando o total no tabuleiro. Caso obtenha sete o jogador deve desenhar uma cobra e perderá o jogo se completar sete cobras, ou se o seu adversário cobrir todos os números do tabuleiro.

Iniciamos a discussão sobre Probabilidade levantando as percepções dos coordenadores sobre o assunto a partir da análise dos conhecimentos matemáticos envolvidos em duas situações de livros didáticos. Partimos, então, para a vivência de um jogo, pois os jogos são atividades excelentes para a introdução de conceitos do campo da Probabilidade e os coordenadores precisavam de maiores subsídios para acompanhar o planejamento e aplicação de situações probabilísticas.

Foto 6: Tabuleiro do Jogo (Jogo das Sete Cobras)

Jogo das Sete Cobras

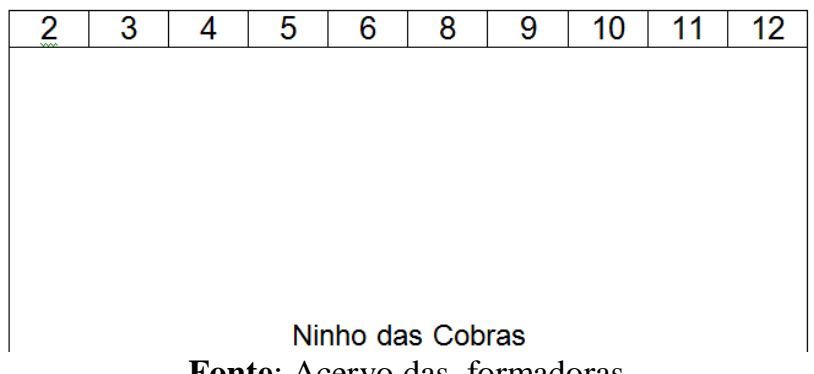

Fonte: Acervo das formadoras

Pelo jogo, os coordenadores perceberam as somas que saíam com maior frequência no lançamento de dois dados, observaram os eventos mais prováveis, menos prováveis, levantaram o espaço amostral do experimento e fizeram o cálculo da probabilidade. Depois, refletiram sobre a potencialidade dessa situação para a sala de aula e decidiram levá-la para as reuniões de formação na escola.

Em seguida, voltaram para as questões iniciais do encontro para elaborarem questões relativas à Probabilidade. Refletimos juntos sobre a importância desse conteúdo

\footnotetext{
${ }^{3}$ Disponível em: <https://goo.gl/YIGH59>. Acesso em: 29 dez.2016.
} 
nos anos iniciais com o estudo do texto Sobre chances e probabilidades, de Célia Maria Carolino Pires, discutindo porque esse conteúdo, embora recomendado desde 1997 pelos PCN, ainda não é de domínio efetivo e prática dos professores (PIRES, 2012). Levantamos como hipóteses a falta de experiências dos professores com o conteúdo, enquanto alunos iniciais e também na Formação Inicial, a pouca exploração pelos livros didáticos e a pouca ênfase sobre os temas da Educação Matemática na escola.

Ressaltamos que é preciso que os professores reconheçam a importância do conhecimento probabilístico, presente no cotidiano, em eventos aleatórios de diversas naturezas, envolvendo acaso e incerteza e a influência destes na vida das pessoas, por exemplo, por jogos de azar, previsão do tempo, eleição, seguro de veículos. Destacamos que as situações que envolvem Probabilidade aguçam o raciocínio, o levantamento de hipóteses, a construção de estratégias e a mobilidade do pensamento e tem relação com outros conteúdos como estatística e números racionais.

\section{Considerações Finais}

O Coordenador Pedagógico pode ser um agente transformador do processo ensinoaprendizagem na escola. No entanto, sabemos a complexidade de atividades como articular as diversas esferas da comunidade escolar, se responsabilizar pelo Projeto Político Pedagógico da escola, promover as mudanças necessárias em algumas práticas pedagógicas.

No entanto, as mudanças não ocorrem de um momento para outro. A formação é o principal meio de transformação na escola, capaz de levar a reflexão necessária para o processo de deslocamento do que se encontra instalado nas pessoas. A colaboração é o impulso que corrobora com esse processo, permitindo que essas se auxiliem mutuamente.

A formação em Matemática, ainda se faz pouco presente nos espaços formativos das escolas dos anos iniciais do Ensino Fundamental, justamente, em um momento tão importante em que as crianças se constituem, tem uma curiosidade natural e uma muita disponibilidade em aprender.

A experiência narrada visou mudar esse quadro, debatendo com os Coordenadores Pedagógicos possibilidades para os seus fazeres, a importância de um processo formativo em Matemática que considere os saberes das crianças, o desenvolvimento do seu 
pensamento, a liberdade de comunicação e a compreensão crítica da linguagem presente no seu cotidiano.

Dessa forma, por meio da descrição dos encontros de formação em Tratamento da Informação, foi possível analisar o papel preponderante do Coordenador Pedagógico na oferta de formação em Educação Matemática aos seus professores, para que estes desenvolvam suas práticas e reflitam sobre elas, garantindo a qualidade do processo educativo de seus alunos.

\section{Referências Bibliográficas}

BORBA, Rute; BATISTA, Rita.; AZEVEDO, Juliana. Levantando possibilidades para o desenvolvimento dos raciocínios probabilístico e combinatório de crianças em anos iniciais de escolarização. In: BORBA, R. \& GUIMARÃES, G. (Org.) Pesquisa e atividades para o aprendizado matemático na Educação Infantil e nos anos iniciais do Ensino Fundamental. Brasília: SBEM, 2015. [livro eletrônico]

CADERNO DE FORMAÇÃO UNIVESP/UNESP. Formação de Professores: Didática dos Conteúdos. bl. 2, v. 7. São Paulo: Cultura Acadêmica Editora, 2012.

GUIMARÃES, Gilda. Estatística nos anos iniciais. In: Salto para o futuro: Estatística e Combinatória no ciclo de alfabetização, ano 14, bol.6, set. de 2014.

LERNER, Délia.; TORRES, Mirta; CUTER, Maria Elena. A tematização da prática na sala de aula. In: CARDOSO, Beatriz. (Org.). Ensinar: tarefa para profissionais. Rio de Janeiro: Record, 2007. p.103-146.

MANDARINO, Mônica Cerbella Freire. A análise de soluções dos alunos na formação de professores que ensinam matemática. In: REUNIÃO ANUAL DA ANPED, 33., 2008, CaxambuMG. Anais... Caxambu: ANPED, GT Formação de professores, 2008.

PESSOA, Cristiane; BORBA, Rute. Quem dança com quem: o desenvolvimento do raciocínio combinatório de crianças de $1^{\mathrm{a}}$ a $4^{\mathrm{a}}$ série. Zetetiké, Campinas, v.17, v. 17, jan/ jun. 2009a.

PIRES, Célia Maria Carolino. Educação Matemática: conversa com professores dos anos iniciais. 1. ed. São Paulo: Zé-Zapt Editora, 2012.

PONTE, João Pedro da. A formação do professor de Matemática: Passado, presente e futuro. In:

EDUCAÇÃO MATEMÁTICA: CAMINHOS E ENCRUZILHADAS, ENCONTRO INTERNACIONAL EM HOMENAEM A PAULO ABRANTES, Lisboa, 2005. Anais... Lisboa: FCUL, 2005.

REIS, Pedro. Observação de aulas e avaliação do desempenho docente. In: Caderno CCAP, n. 2 , jun. de 2011. Disponível em: < http://www.ccap.min-edu.pt/docs/Caderno_CCAP_2Observacao.pdf > Acesso em: 14 dez. 2016. 
SALVADOR. Secretaria Municipal da Educação, Cultura, Esporte e Lazer. Coordenador pedagógico: caminhos, desafios e aprendizagens para a prática educativa. Salvador: Avante Educação e Mobilização Social, 2012. 92 p.

SANTANA, Michaelle Renata Moraes de.; BORBA, Rute Elizabete de Souza Rosa. Ensino de probabilidade: o que os livros sugerem, o que os professores conhecem. In: ENCONTRO DE COMBINATÓRIA, ESTATÍSTICA E PROBABILIDADE DOS ANOS INICIAIS, Pernambuco, 2016. Anais eletrônicos... Pernambuco: ENCEPAI, 2016.

SMOLE, Kátia Stocco.; DINIZ, Maria Inês. Ler, escrever e resolver problemas: habilidades básicas para aprender matemática. Porto Alegre: Artmed, 2001.

ZEN, G.C. O papel da Coordenação Pedagógica na escola. In: Salto para o Futuro: Coordenação Pedagógica em foco, Brasília, ano 12, bol.1, abr. de 2012.

Recebido em 29/03/2017 - Aceito em 13/06/2017 